\title{
CONSIDERATION ON SUPERIOR CAPITALIZATION OF WINE BY-PRODUCTS
}

\author{
Oana Cristea, Carmen Bracacescu, Dumitru Milea, Larisa Cristea \\ National Institute of Research-Development for Machines and Installations \\ Designed to Agriculture and Food Industry, Romania \\ diana10cristea@gmail.com, carmenbraca@yahoo.com,milea_dumitru57@yahoo.com, \\ larisacristea91@yahoo.com
}

\begin{abstract}
Following the processing of the grapes to obtain the finished product, a series of by-products and waste can be recovered (bunch, pomace, tartar, etc.), and through their processing, good protection of the environment is also ensured. An increasingly interesting and up-to-date segment is the study and capitalization of wine by-products, due to the fact that the wine by-products (pomace, grape seeds) have a complex biochemical composition, being noted for their content in mineral elements, fibre, vitamin $\mathrm{C}$ and phenolic compounds (tannins, phenolic acids, anthocyanins and resveratrol).The complex capitalization of wine byproducts is determined by their high weight (between 18-20\% of the quantity of grapes processed, and the byproduct with the highest weight is pomace), also of the substances they contain, being useful to different industries (food, cosmetic, pharmaceutical, etc.). The paper presents an analysis of representative technologies for the superior capitalisation of the wine by-products and of the technical equipment underlying them, together with some relevant theoretical aspects regarding the separation process of grape seeds that were the basis for design and realization of the technical equipment for separating grape seeds from pomace ESSS. This equipment performs the separation of the fractions by combining the principle of separation on flat sieves with oscillatory movement by thickness, with the separation in air flows according to the floating velocity of the fractions, ensuring a high purity of grape seeds for further processing. Also, in the feeding process the material is subjected to a process of crushing and decompaction thus substantially facilitating the separation of grape seeds from pomace. At the end of the paper, the advantages of using the innovative technology for the recovery of byproducts from viticulture and the technical equipment for separating grape seeds from pomace ESSS are presented.
\end{abstract}

Keywords: technologies, wine by-products, pomace, capitalisation.

\section{Introduction}

After each technological operation during winemaking from grapes or wine conditioning, byproducts result with physical-chemical properties varying according to numerous ecological, technological and biological factors [1].

In literature, wine by-products are represented by the extracts from the material obtained after grape processing (known as the "pomace"), which can no longer be used in that processing process. Pomace represents all the vegetable parts of the grapes used to obtain the must or wine through the pressing process, such as: bunches, skins and seeds, depending on the grape variety. It can be unfermented (fresh) or at different stages of alcoholic fermentation.

At the same time, due to the increasing attention to sustainable agricultural and consumer demand for the use of natural over synthetic compounds, there is great interest in the utilization of grape byproducts as food additives, nutraceuticals, ingredients of functional foods/dietary supplements, medical remedies, fertilizers, animal feed, antimicrobial components, cosmetics and as biomass for biofuels $[2 ; 3]$. Research carried out both internally and externally showed that grape seeds contain, mainly, phenolic compounds, and due to their antioxidant capacity, grape seeds have anti-allergic, anti-inflammatory, anti-carcinogenic, immune-boosting action and beneficial effects in cardiovascular diseases [3;4]. Therefore, the correct management of the by-products from wine industry has a significant impact both on the environment and from economic point of view due to the multiple possibilities of use.

The trend of superior capitalization of wine by-products has led to the development of various separation methods that use complex equipment, which includes in their components systems for prepreparation of the seed mixture before the actual separation [5-8].

The paper presents some theoretical aspects regarding the grape seed separation process based on combine principle, in analogy to those used to separate cereal seeds, using oscillating sieves and an air cleaning system, which led to the elaboration of an innovative technology for the recovery of by- 
products from viticulture, which main component is the technical equipment for separating grape seeds from pomace ESSS designed and realized as an experimental model at INMA Bucharest.

\section{Materials and methods}

Rational processing of the by-products resulted from the wine industry using modern technologies with ecological measures to protect the environmental factors offers the possibility to obtain addedvalue products.

A better knowledge of grape pomace composition enables to evaluate the importance of the raw material variability on the final application [4]. Thus, one of the current challenges is the reclassification of such waste as by-product that can be reprocessed, aiming to reduce the negative impacts on the environment, as well as to obtain high added value materials.

Solid waste from pomace consists of: skins (55-65\%), seeds (18-25\%) and liquid residues (must or wine).

The method of capitalizing of the grape pomace presented in Fig. 1 mainly aims at separating the grape seeds from the grape skin and other plant parts. Before the pomace is separated, it must be decompacted in order to make the separation process more efficient. In this technology transport and feedstock equipment are also provided.

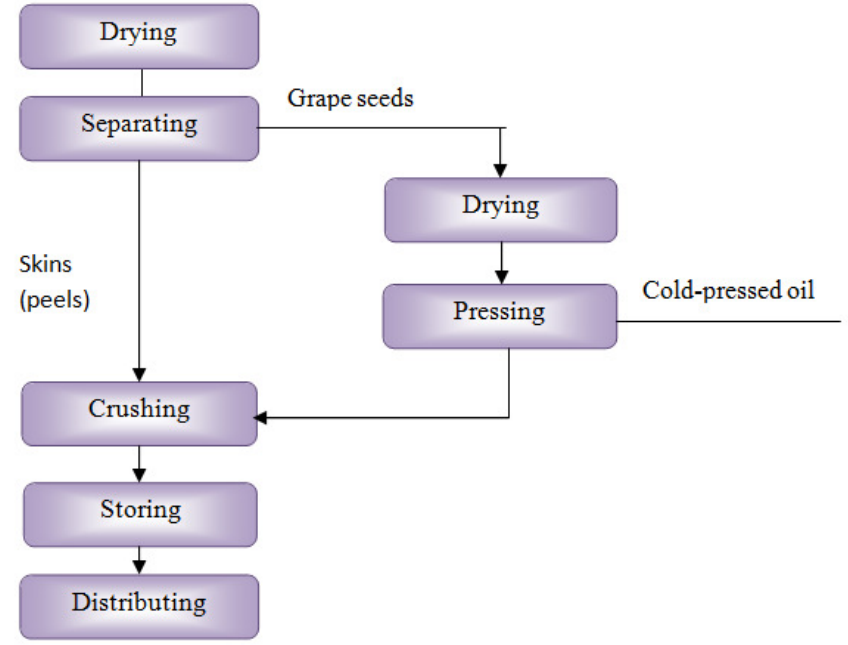

Fig. 1. Operational flow diagram of grape pomace capitalization method

In order to perform the separation operation, it is recommended to use equipment that operates on the principle of separation according to the aerodynamic properties, being generated an air flow in the opposite direction of the material displacement to direct the skins through an outlet towards the milling operation performed by a hammer mill that crushes them; then they are stored in bunkers, from where they can be unloaded in the trailer of the loading machines $[5 ; 6 ; 9]$. On the other hand, the grape seeds that were separated will be picked up by a conveyor and placed in a drying room, to be brought to a humidity that will not exceed $12 \%$. The storage of these seeds is recommended to be made for short periods of time, if it is not possible for the milling and oil extraction operations to be carried out immediately. The pomace mixture is biphasic (solid material with high humidity), and it is composed of seeds and skins that are initially compact, because this material is obtained after the pressing process. The separation process can be compared with washed cereal separation process - the first separation operation and by size - the second separation operation.

In order to carry out the process of aerodynamic separation of a mixture of solid particles, respectively seeds and skins, it is necessary to consider a number of factors that have a major impact on the way it takes place, among which we mention:

- properties of solid particles subject to aerodynamic separation;

- airflow properties, respectively the airflow direction and the flow regime;

- the way the biphasic mixture gas-solid (G-S) is made. 
The resistance of the seed mass layer to the passage of air or gas is a property of particular interest for the processes of aeration, gassing, drying, etc. [10], and the total resistance of the granular material layer to the passage of air or gas is calculated with equation (1),

$$
R=A \cdot h \cdot W^{n},\left(\mathrm{~mm} \mathrm{H}_{2} \mathrm{O}\right)
$$

where $h$-thickness of the material layer, m;

$W$ - conventional velocity of air or gas relative to the entire section of the seed layer, $\mathrm{m} \cdot \mathrm{s}^{-1}$;

A, $n$ - coefficients determined experimentally according to the characteristics of the seeds.

In the case of machines that use as a separation principle the separation according to the aerodynamic properties, the floating velocities of seeds and impurities and also the aerodynamic coefficient, respectively, must be considered [11]:

$$
\begin{gathered}
v_{p}=\sqrt{\frac{\rho_{p \frac{\pi d^{3}}{6}}}{0.124 k \frac{\pi d^{2}}{4}},} \\
v_{p}=2.4 \sqrt{\frac{\rho_{p}}{k} d},
\end{gathered}
$$

where $v_{p}$ - floating velocity, $\mathrm{m} \cdot \mathrm{s}^{-1}$;

$\rho_{p}$ - specific mass of the particle (ideal case of spherical seed), $\mathrm{kg} \cdot \mathrm{m}^{-3}$;

$d$-particle diameter, $\mathrm{m}$;

$k$ - aerodynamic drag coefficient (depends on the state of the particle surface).

Knowing the floating properties of the particles of a mixture having as main component seeds in air flows gives important indications for the correct choice and adjustment of the air flow velocity for the calculation and design of the pneumatic systems intended for seed mixture separation.

\section{Results and discussion}

The innovative technology for the recovery of by-products from viticulture elaborated by INMA is given in Fig. 2 and is based on a complex process of pomace processing realized by pieces of technical equipment arranged in a logical order to ensure a technological flow within which three main phases are distinguished:

- phase I - coarse separation of the non-homogeneous mixture components;

- phase II - obtaining the dry mass;

- phase III - fine separation of the non-homogeneous mixture components.

All these phases can be interconnected by inter-phase transport operations of the by-products that will be monitored through a command and control unit - CCU.

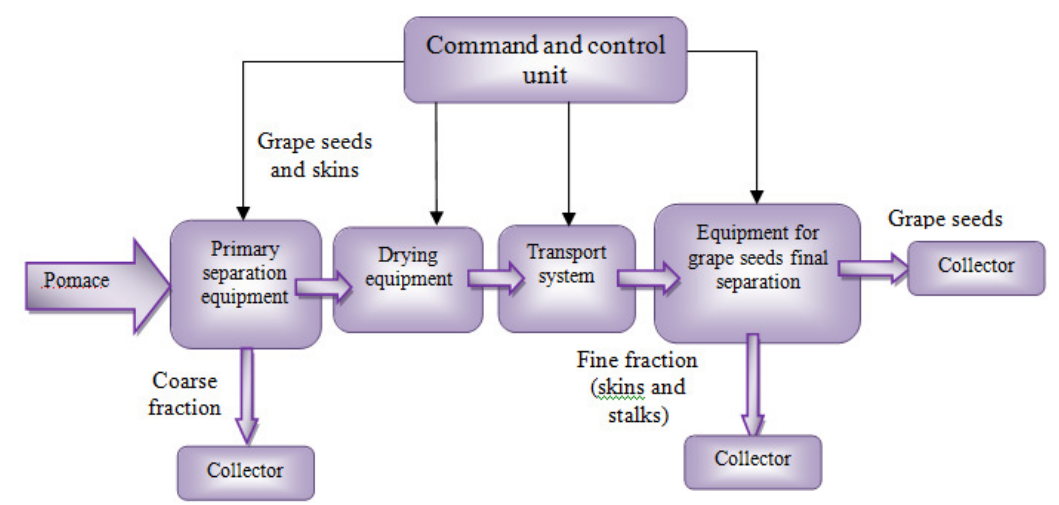

Fig. 2. Technology for processing the wine by-products in order to separate the grape seeds 
Following pomace processing within this technological flow finished products are obtained, respectively grape seeds, skins and stalks, which can subsequently be used to obtain new products with applications in the food, cosmetic and pharmaceutical industry.

Within this technology, the technical equipment for separating grape seeds from pomace - ESSS was developed, equipment with which the separation of grape seeds from unfermented pomaceis carried out, which has previously been brought to a humidity of $12-15 \%$ by drying with special equipment. The separation of the fractions is done by combining the principle of separation on flat sieves with oscillatory movement by thickness, with the separation in air flows according to the floating velocity of the fractions [10].

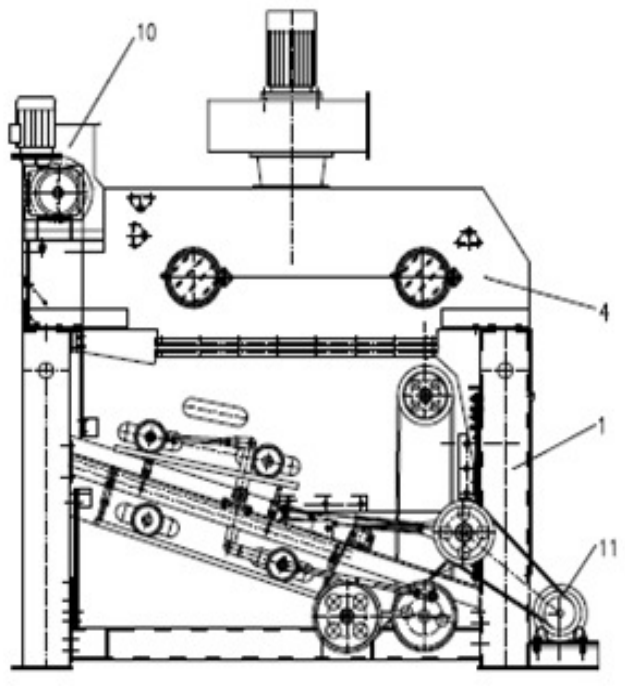

lateral view

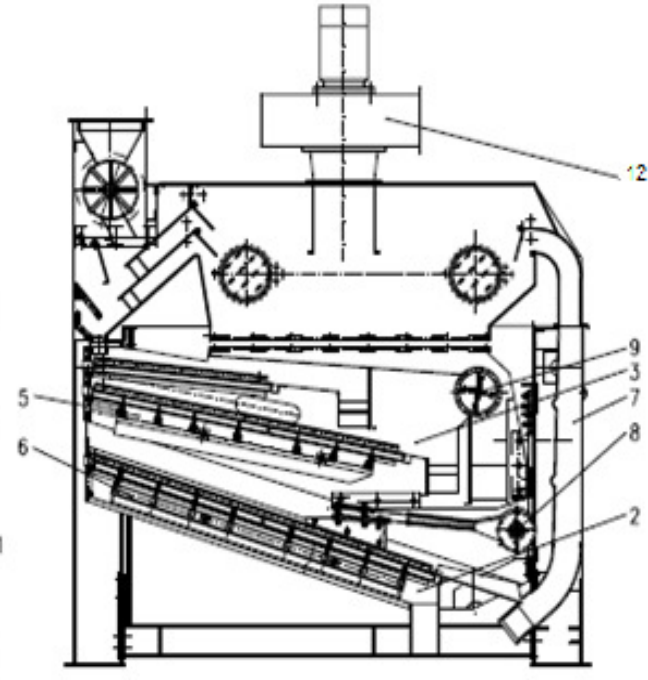

longitudinal section

Fig. 3. Constructive scheme of the technical equipment for separating grape seeds from pomace ESSS: 1 - support frame; 2 - lower frame; 3 - higher frame; 4 - aspiration chamber; 5 - brush support 1; 6 - brush support 2; 7 - aspiration channel; 8 - eccentric shaft; 9 - pallet shaft; 10 - feed system; 11 - electric motor; 12 - fan

Fig. 3 shows the constructive scheme of the experimental model ESS. The feed system (pos. 10) is mounted at the entrance of the product to be processed (dried pomace), having the role of decompacting and overturning it, in order to crush and remove the grape seeds remaining stuck in the grape skins. The aspiration chamber (pos. 4) is provided with channels for aspirating light impurities and dust both at the entry of the raw product into the machine and at the evacuation of the cleaned finished product. Also, it is provided inside with 3 flaps for adjusting the working parameters of the air flows generated by the fan, with a flap to standardize the product flow across the working width at the exit of the chamber and with four sight glasses that allow monitoring the impurities separation process. The raw material feed system and the aspiration fan are mounted on the aspiration chamber.

Technical and functional characteristics of the ESSS:

- working capacity: $500-600 \mathrm{~kg} \cdot \mathrm{h}^{-1}$;

- installed power: $7.5 \mathrm{~kW}$;

- sieves' working width: $600 \mathrm{~mm}$;

- overall dimensions LxDxH: 2750x1400x2700 mm.

The working process of the equipment for separating grape seeds from pomace - ESSS is shown in Fig. 4.

The product to be processed (the mixture of dried pomace) falls on a system of inclined planes, where the aspiration of light impurities (dust and very small skins) takes place. After that, the raw material is separated by means of oscillating sieves. The evacuation of the air used in the separation process is done by a fan (position 9) that can be connected to a supercyclone. The sieves are equipped with brush cleaning systems (position 12), which are mounted on mobile trolleys. The brush supports 
receive the forward and backward movement from the main drive by means of an eccentric wheel and some levers and joints, as it is shown in Fig. 5.

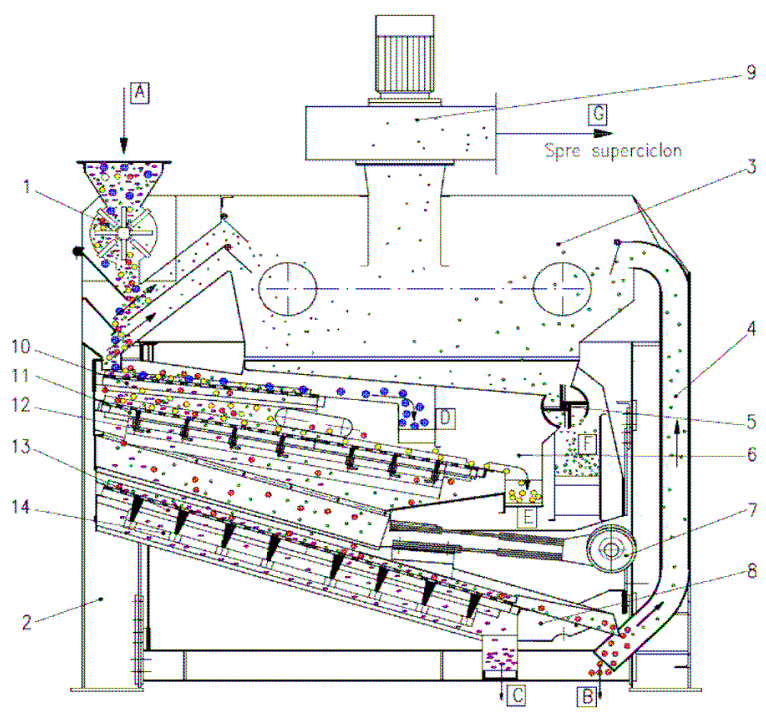

Fig. 4. ESSS working scheme: A - raw material feed; B - cleaned product (grape seeds); C - small impurities; D - coarse impurities; E - large plus material (skins) F - light impurities; G - dust;

1 - feed system; 2 - frame; 3 - aspiration chamber; 4 - aspiration channel; 5 - lock; 6 - higher frame; 7 - eccentric shaft; 8 - lower frame; 9 - aspiration fan; 10 - sieve $1 ; 11$ - sieve 2;

12 - brush support $1 ; 13$ - sieve $3 ; 14$ - brush support 2

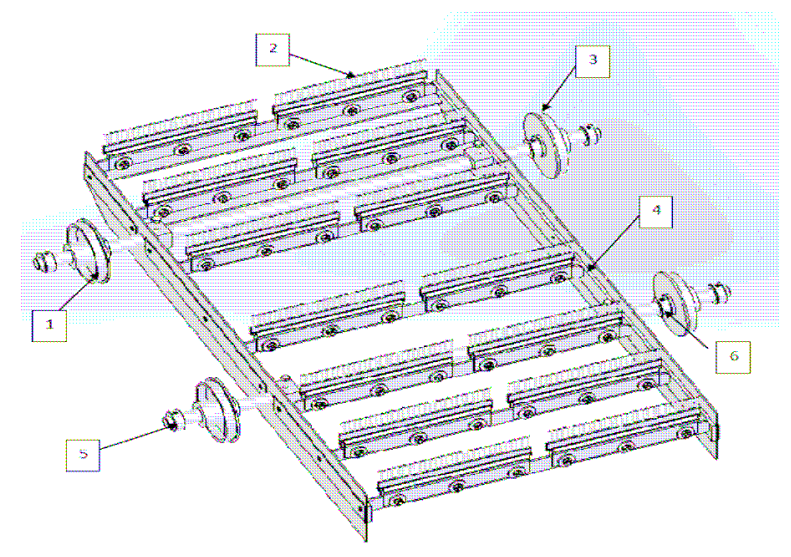

Fig. 5. Overall drawing of brush support: 1 - frame; 2 - brush; 3 - roller pulley; 4 - axle II; 5 - ring I; 6 - ring II

\section{Conclusions}

1. The technical equipment for separating grape seeds from pomace ESSS developed within the innovative technology for the recovery of wine by-products elaborated by INMA presents the following advantages:

- the existence of systems for adjusting the air flows designed so as to ensure a finer adjustment of their velocity;

- achieving an advanced decompaction of the pressed pomace by equipping with a system for cleaning the active elements in the separation process;

- ensuring a high degree of the useful fraction final separation having a small percentage of secondary components injured in the working process.

2. The innovative technology is developed to achieve the separation of valuable components from the mixture resulting from the winemaking process (seeds, skins, stalks) in a continuous flow and 
can be adapted to the requirements of the beneficiaries. The application of the new technologies will facilitate the most efficient extraction of the fractions from pomace containing specific active principles.

3. The beneficiaries of this technology can be: wine companies, economic agents producing organic vegetable oils, as well as producers in the phytopharmaceutical industry.

\section{Acknowledgements}

This paper was financed by:

- the support of the National Agency for Scientific Research and Innovation, Programme SECTORAL PLAN (Contract No.2PS / 28.08.2019), project P 2.1.2 "Research on the fortification of food products with functional ingredients obtained from wine by-products",

- a grant of the Romanian Education and Research Ministry, through Programme 1 Development of the national research-development system, subprogramme 1.2 - Institutional performance - Projects for financing excellence in RDI, contract No. 16PFE.

\section{References}

[1] Balteș M. Identification and characterization of useful by-products of grape wine products, case study: wine yeast. Proceeding of the International Conference Agri-Food Sciences, Processes and Technologies, Agri-Food, Sibiu, Romania, May, 2015.

[2] Maier T., Schieber A., Kammerer D. R., Carle R. Residues of grape (Vitis vinifera L.) seed oil production as a valuable source of phenolic antioxidants. Food Chemistry, vol. 112, (3), 2009, pp. 551-559.

[3] Jayaprakasha G.K., Selvi T., Sakariah K.K. Antibacterial and antioxidant activities of grape (Vitis vinifera) seed extracts. Food Research International, vol. 36, (2), 2003, pp. 117-122.

[4] Patti A. F., Issa G. J., Smernik R., Wilkinson K. Chemical composition of composted grape marc., Water Sci Technol., vol. 60 (5), 2009, pp. 125-371.

[5] Rus Fl. Separation operations in the food industry. Publishing Transylvania University of Brasov, ISBN-973-8124-31-X, 2001, pp. 75-101.

[6] Păun A., Stroescu Gh., Vișan A.L., Olan M,, Zaica A., Moiceanu G. Researches regarding the optimization of impurities removal technology from the cereal and industrial plant seeds for establishing ecological crops, INMATEH Agricultural Engineering, vol.56, no.3, 2018, pp. 83-90.

[7] Peraza A.L., Pena J.G., Segura Jauregui J.S., Vizcarra M., Dehydration and Separation of Grape Pomace in a Fluidized Bed System, Journal of Food Science, vol.51, 2006, pp. 206-210.

[8] Casa L., Mantell C., Rodriguez M., Martinez de la Ossa E.J., Extraction of resveratrol from the pomace of Palomino fino grapes by supercritical carbon dioxide, Journal of Food Engineering, vol.96, 2010, pp. 304-308.

[9] Brăcăcescu C., Ţenu I., Mircea C., Bunduchi G. Experimental research on influence of functional parameters of combined installations designed at separating the impurities out of cereal seeds. Proceedings of 8th International Conference on "Thermal Equipment, Renewable Energy and Rural Development, TE-RE-RD 2019”, E3S Web-of-Conferences Open Access proceedings in Environment, Energy and Earth Sciences, vol.112, (eISSN: 2267-1242), Târgovişte, România.

[10] Stroescu G., Păun A., Voicu G., Brăcăcescu C., Popa R., Popa V. Researches on the separation of impurities from a seed flow based on the aerodynamic principle. Proceedings of 8th International Conference on "Thermal Equipment, Renewable Energy and Rural Development, TE-RE-RD 2019", E3S Web-of-Conferences Open Access proceedings in Environment, Energy and Earth Sciences , vol.112, (eISSN: 2267-1242), Târgovişte, România.

[11]Barsky E., Barsky M. Relationship between fractional separation curves and quantitative optimization criteria in the separation of pourable materials. Physical Separation in Science and Engineering, vol. 13, 2004, pp. 41-51. 